\title{
EDITORIAL
}

\section{In This Issue: Clinical Decision Support}

\author{
Kurt C. Stange, $M D, P b D$, Editor
}

Ann Fam Med 2011;9:2. doi:10.1370/afm.1215.

M ost of the research in this issue is about supporting good clinical decisions, actions, and communication.

Three clinical trials ${ }_{1}^{1-3}$ a cohort study ${ }_{1}^{4}$ and a systematic review ${ }^{5}$ address formal clinical decision support.

Ruffin and colleagues evaluate a self-administered, Web-based tool for assessing familial risk and providing messages about health behavior change and screening that are personalized on the basis of familial risk. ${ }^{1}$

$\mathrm{O}^{\prime}$ Connor et al find that clinical decision support embedded within an electronic health record can modestly improve control of diabetes and hypertension but not affect low-density lipoprotein cholesterol. ${ }^{2}$

Gill and colleagues, in a national, practice-based research network, find a mixed effect of electronic health record alerts for high-risk patients on prescription of nonsteroidal anti-inflammatory agents. ${ }^{3}$

Van der Velde et al find that 2 clinical decision rules, in combination with point-of-care D-dimer testing, can exclude deep venous thrombosis and reduce unnecessary further testing by one-half.

Ebell and Afonso search the literature for multivariate models and clinical decision rules to diagnose influenza. They find modest accuracy for the heuristics of "fever and cough" and "fever, cough, and acute onset."

Together, these studies show that clinical decision aids for either patients or clinicians, can have some effect on improving health care and health behaviors.

Other articles in this issue evaluate contextual factors affecting the clinical decision-making processes.

McKee et al in a qualitative study find that clinicians in urban health centers focus on periodic preventive care visits as the key time to offer time for confidential discussions to adolescent patients. ${ }^{6}$

Studying the policy context for medical decision making, Lesser and colleagues find a mismatch between the financial incentives and the evidence for preventive care for older Americans. ${ }^{7}$

Zayas et al evaluate traditional care for asthma based on the cultural beliefs and practices of Puerto Rican Americans. ${ }^{8}$ The typology of remedies emerging from this research can help clinicians to consider more fully the cultural context for health care decision making.
Fiscella analyzes how recent US health care reform legislation presents an opportunity for improved equity. ${ }^{9}$

In one of the 2 methodology studies in this issue, Westfall et $a 1^{10}$ update use of the weekly return card as a fundamental method for practice-based network research. This method was pioneered more than 2 decades ago by the Ambulatory Sentinel Practice Network. ${ }^{11,12}$ With another study, Liddy and colleagues advance understanding of methods for fostering interrater reliability in medical record review. ${ }^{13}$

\section{References}

1. Ruffin MT IV, Nease DE Jr, Sen A, et al. Effect of preventive messages tailored to family history on health behaviors: the Family Healthware Impact Trial. Ann Fam Med. 2011;9(1):3-11.

2. O'Connor PJ, Sperl-Hillen JM, Rush WA, et al. Impact of electronic health record clinical decision support on diabetes care: a randomized trial. Ann Fam Med. 2011;9(1):12-21.

3. Gill JM, Mainous AG III, Koopman RJ, et al. Impact of EHR-based clinical decision support on adherence to guidelines for patients on NSAIDs: a randomized controlled trial. Ann Fam Med. 2011;9(1): 22-30.

4. van der Velde EF, Toll DB, ten Cate-Hoek AJ, et al. Comparing the diagnostic performance of 2 clinical decision rules to rule out deep vein thrombosis in primary care patients. Ann Fam Med. 2011;9(1): 31-36.

5. Ebell MH, Afonso A. A systematic review of clinical decision rules for the diagnosis of influenza. Ann Fam Med. 2011;9(1):69-77.

6. McKee MD, Rubin SE, Campos G, O'Sullivan LF. Challenges of providing confidential care to adolescents in urban primary care: clinician perspectives. Ann Fam Med. 2011;9(1):37-43.

7. Lesser LI, Krist AH, Kamerow DB, Bazemore AW. Comparison between US Preventive Services Task Force recommendations and Medicare coverage. Ann Fam Med. 2011;9(1):44-49.

8. Zayas LE, Wisniewski AM, Cadzow RB, Tumiel-Berhalter LM. Knowledge and use of ethnomedical treatments for asthma among Puerto Ricans in an urban community. Ann Fam Med. 2011;9(1):50-56.

9. Fiscella K. Health care reform and equity: promise, pitfalls, and prescriptions. Ann Fam Med. 2011;9(1):78-84.

10. Westfall JM, Zittleman L, Staton EW, et al. Card studies for observational research in practice. Ann Fam Med. 2011;9(1):63-68.

11. Green, LA. The weekly return as a practical instrument for data collection in office based research. Fam Med. 1988. 20(3):182-184.

12. Green LA, Reed FM, Miller RS, Iverson DC. Verification of data reported by practices for a study of spontaneous abortion. A report from ASPN. Fam Med, 1988. 20(3):189-191.

13. Liddy C, Wiens $M$, Hogg W. Methods to achieve high interrater reliability in data collection from primary care records. Ann Fam Med. 2011;9(1):57-62. 